\title{
Damage tolerance of fractured rails on continuous welded rail track for high-speed railways
}

\author{
Yuan Gao $^{1,2} \cdot$ Ping Wang ${ }^{1,2} \cdot$ Kai Wang ${ }^{1,2} \cdot$ Jingmang Xu ${ }^{1,2} \cdot$ Zhiguo Dong $^{1,2}$
}

Received: 6 August 2020/Revised: 1 November 2020/Accepted: 4 November 2020/Published online: 14 December 2020

(C) The Author(s) 2020

\begin{abstract}
Broken gap is an extremely dangerous state in the service of high-speed rails, and the violent wheel-rail impact forces will be intensified when a vehicle passes the gap at high speeds, which may cause a secondary fracture to rail and threaten the running safety of the vehicle. To recognize the damage tolerance of rail fracture length, the implicit-explicit sequential approach is adopted to simulate the wheel-rail high-frequency impact, which considers the factors such as the coupling effect between frictional contact and structural vibration, nonlinear material and real geometric profile. The results demonstrate that the plastic deformation and stress are distributed in crescent shape during the impact at the back rail end, increasing with the rail fracture length. The axle box acceleration in the frequency domain displays two characteristic modes with frequencies around 1,637 and $404 \mathrm{~Hz}$. The limit of the rail fracture length is $60 \mathrm{~mm}$ for high-speed railway at a speed of $250 \mathrm{~km} / \mathrm{h}$.
\end{abstract}

Keywords Rail broken gap · Explicit FE method - Damage · High-frequency impact · Stress mechanism

Jingmang $\mathrm{Xu}$

mang080887@163.com

1 MOE Key Laboratory of High-Speed Railway Engineering, Southwest Jiaotong University, Chengdu 610031, China

2 School of Civil Engineering, Southwest Jiaotong University, Chengdu 610031, China

\section{Introduction}

As an infrastructure for vehicles running on high-speed rails, track is a critical component that directly bears the multi-field coupling effect of vehicle and temperature load. During the long-term service of rails, under the effect of cyclic dynamic wheel load, construction deficiency and temperature effect, the rails are subject to various damages (see Fig. 1). In the section of seamless rails, the changes in temperature can cause enormous temperature force inside rails, thereby causing them to break eventually. To name a few, the rail of the upper line at K489 + $140 \mathrm{~m}$ on Hengyang-Liuzhou railway was broken, the rail of the upper line at $\mathrm{K} 2322+490 \mathrm{~m}$ on Guangzhou-Shenzhen-Hong Kong high-speed railway was broken vertically, and the base metal of the rail of the upper line at K359 + 790 m on Qingdao-Jinan railway line was broken (see Fig. 1). It has been admitted that the rail fracture is an unpredictable and extremely dangerous damage that seriously threatens the running safety of vehicles (Fig. 2).

The rail fracture has a great significant influence on wheel-rail interaction and running safety of vehicles. In terms of geometric properties, after rails are broken the geometry and continuity of tracks are destroyed, which is mainly represented by three factors: broken gap, step and bending angle. Moreover in terms of mechanical properties, the geometrical discontinuity of rails caused by the broken gap results in the loss of the vertical bending stiffness of rails. For this reason, during the wheel passing over the broken gap, a violent dynamic force of wheel-rail impact will be excited, aggravating the wheel-rail interaction and vibration of rail. In addition, most of the rail fracture can be detected by a safety system; however, due to the complex layout of track circuit wire in turnout, there still remains some rail broken gap in turnout that cannot be 



Fig. 1 Formation reasons of broken gap

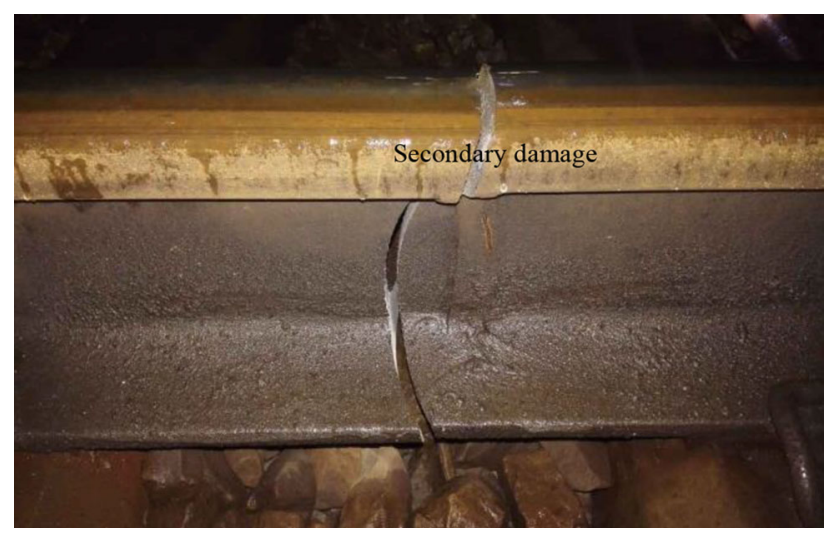

Fig. 2 Steel rail fracture with secondary fracture detected by the safety system (see Fig. 3). The track circuit can work normally when a rail is broken. In addition, there exists transverse track circuit wire at the heel of the frog; therefore the broken rail cannot be detected by the track circuit wire. The real-time monitoring of the rail broken gap through track circuit wire in turnout has not been realized. As the occurrence frequency of rail fractures in high-speed railways is uncertain, if it cannot be detected in time, it will aggravate the damage to the rails or even threaten the traffic safety.

China Academy of Railway Sciences (CARS) carried out a safety test on a vehicle passing the rail with broken gap, in which the speeds of the vehicle were $20 \mathrm{~km} / \mathrm{h}$ and $85 \mathrm{~km} / \mathrm{h}$, respectively. CHN50 rails and ballast track bed as well as wooden sleepers were used in the test line. The test measured the lateral displacement of the front rail, and the step value (height difference between the front rail and back rail under wheel load), and evaluated the running safety of the vehicle based on the degree of crescentshaped damage at the free broken gap end [1]. However, the test method held certain limitations: the velocity of the train was relatively low compared to the high-speed railway, and the wheel-rail contact stress could not be directly and accurately measured by instrument. For this reason, aiming at the high-frequency wheel-rail impact at broken gap and its influence on running safety, many scholars have used the numerical simulation method for safety analysis. Suare et al. [2, 3] proposed a numerical simulation method by considering the train-track interaction to investigate the dynamic derailment behavior at the broken rail and then the running safety during the passage of an underground vehicle over the highly resilient straight and curved slab tracks. Schafer et al. [4] analyzed the factors of derailments caused by a mainline broken rail and proposed a feasible tool which is capable of identifying locations with a high probability of rail fracture by considering the rail mechanism characteristics, infrastructure information, maintenance and operational conditions. Allan [5] focused on the risk management techniques in controlling derailment of vehicles on broken rails and put forward the guidelines to

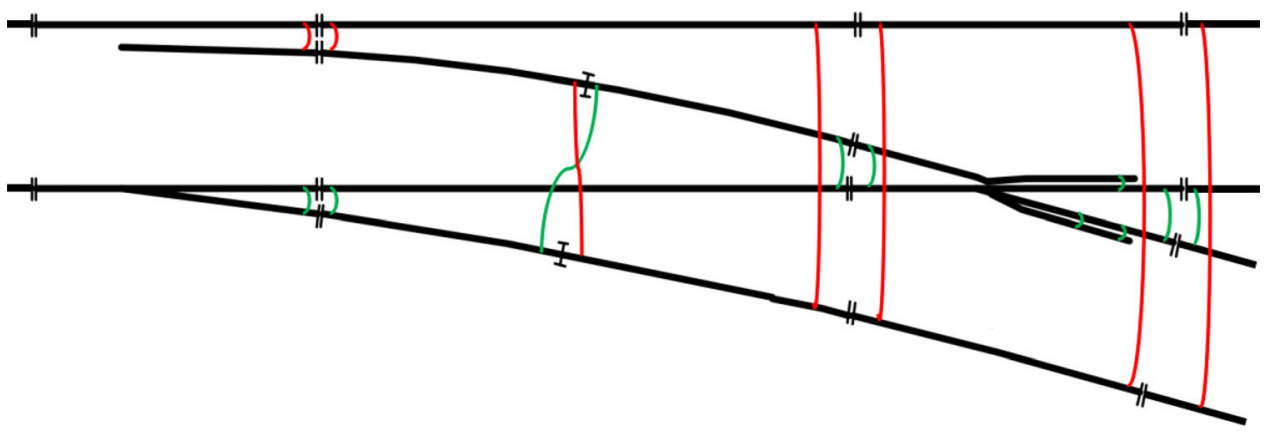

Fig. 3 Schematic diagram of track circuit wire in turnout 
reduce the risk of derailments of vehicles on broken rails. Matsuda [6] conducted a survey about the relationship between the occurrence of flaking leading to the rail breakage and rail wear by on-site investigations and found that the balance between the wear and fatigue is the key factor for flaking damage. Cai et al. [7] proposed a vehicletrack-bridge coupling model with commercial software ABAQUS and investigated the influence of factors including the rail gap position, gap width and velocities on the dynamic response of wheel-rail interaction. Ekberg et al. [8] compared experiences of broken rails in different countries, which is beneficial for networks to assess if a good control on stress free temperatures can be guaranteed. Magel et al. [9] investigated the reasons and conditions of derailment at broken rails and proposed the methods to minimize the occurrence probability of broken rails, which can provide a better understanding and mitigating strategies to reduce the risk of failures. Tai et al. [10] investigated the influence of rail service age, annual traffic density and inspection frequency on the derailment risk of a vehicle at the broken rail and established the preliminary risk analysis model for the prediction of broken rail risks, which can potentially aid to mitigate derailment risk. Sheperd et al. [11] investigated the effect of rolling contact fatigue on multiple fractures of rail, found that the rail fracture occurred in the vicinity of obstacles with the BNSF railway broken rail data, and revealed the occurrence frequency of rail breaks. An et al. [12] proposed a grid-based analysis model for the effects of casual factors on rail break risk based on the Cox's proportional hazards regression analysis method and compared the simulation results with the data of broken rails and casual factors, which can provide accurate understanding of the mechanism of rail break. Most research mainly concerns the effect of broken gap on the running safety of vehicles [13-19], whereas a few consider the wheel-rail contact behavior or even the secondary fracture caused by the wheel-rail impact if the rail fracture is not detected timely [20-23]. In addition, there is no experiment data of ballastless rail gap in China. In the Temporary Standard for New Railway Passenger Dedicated Line Design at the Speed of $250-350 \mathrm{~km}$, the gap value is set as $70 \mathrm{~mm}$, which is determined by engineering experience [7]. Recently, the explicit finite element method has become an efficient and feasible method, which is capable to simulate the dynamic response of wheel-rail high-frequency impact and determine the length of broken gap.

In this paper, to recognize the secondary fracture of rail and determine the tolerance of rail fracture length, a threedimensional explicit finite element model of rail fracture is established to simulate the process where wheels impact the back rail at the broken gap, and the wheel-rail dynamic high-frequency impact and vehicle running safety as well as the stress mechanism of the rails at the broken gap are investigated; then the possibility of secondary fracture to the back rail under the effect of high-frequency impact can be evaluated, which can provide a certain reference for the service and maintenance of steel rails.

\section{Finite element model of broken gap}

Figure 4 illustrates the explicit finite element model for the simulation of wheel-rail interaction at broken gap for highspeed railways. The model is of $25 \mathrm{~m}$ length and mainly consists of the wheel, rail, fasteners and other components closely related to wheel-rail dynamic response. The profile of the rail model is selected according to the standard CHN60 used on the high-speed railway, while the geometric profile of the wheelset is LMA. In the explicit finite element model, the broken gap is located in the middle of the rail to simulate the most unfavorable condition, which can be modeled by deleting the solid elements of the rail.

As shown in Fig. 4, the wheelsets and rails are simulated by 8-node hexahedral elements SOLID165 with the onepoint integration method. In order to reduce the calculation
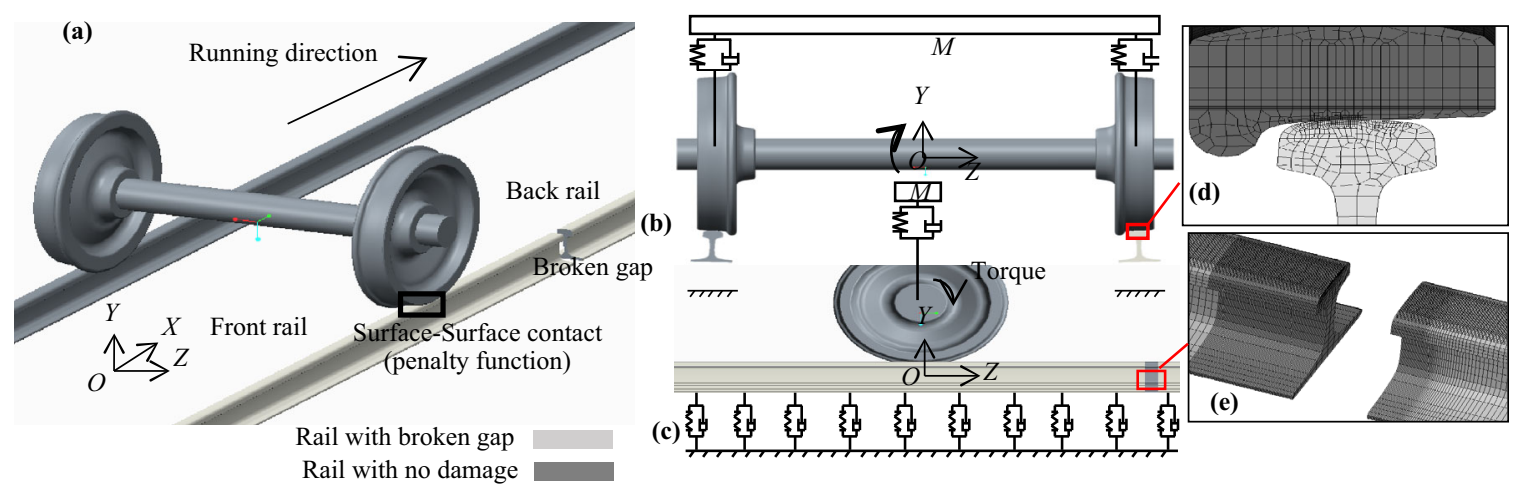

Fig. 4 Wheel-rail interaction model with a close-up of mesh 
amount and guarantee the accuracy of the contact solution, the ALE (arbitrary Lagrange-Euler) self-adaptive mesh is adopted in the model to ensure that the quality of element under violent wheel-rail impact force remains high. The ALE self-adaptive method combines the features of Lagrange algorithm and Euler algorithm, which is mainly used to keep the high quality of elements during the simulation process; therefore, no huge distortions and deformation will occur. The main principle for the ALE selfadaptive method is to detach the element and material, and then, the element will flow independently. In addition, the ALE self-adaptive method does not change the topology of the element. The element size in the potential contact regions around the broken gap is $1 \mathrm{~mm}$, while the maximum element size in the non-contact regions can reach up to $20 \mathrm{~mm}$. The fasteners can be simulated by linear springs and viscous dampers; thus, only the stiffness and damping of the fasteners which are closely associated with wheelrail interaction are considered. After many trials, the single rubber pad is modeled by a $7 \times 7$ discretely distributed spring-damper pairs, which can effectively reduce the influence of the concentrated load. The total stiffness and damping of a fastener are $22 \mathrm{MN} / \mathrm{m}$ and $200 \mathrm{kNs} / \mathrm{m}$, respectively; the stiffness and damping for the each springdamper pair are $0.44898 \mathrm{MN} / \mathrm{m}$ and $4.0816 \mathrm{kNs} / \mathrm{m}$, respectively. As the vibration wavelength of the sprung mass is always expressed in meters [16], which is much longer than the size of contact patch $(10 \mathrm{~mm})$, the wheelrail contact solutions will not be influenced by the sprung mass vibration. For this reason, the body, bogie and other components over the primary suspension can be simplified as a rectangular rigid body supported on the wheelset axle through the primary suspensions. The primary suspension is also simulated by linear springs and viscous dampers, its total stiffness and damping being $0.88 \mathrm{MN} / \mathrm{m}$ and $4 \mathrm{kNs} / \mathrm{m}$, respectively. The stiffness and damping for each springdamper pair are $0.01796 \mathrm{MN} / \mathrm{m}$ and $0.0816 \mathrm{kNs} / \mathrm{m}$, respectively. Moreover, the axle load is $16 \mathrm{t}$. The material of U71Mn rail steel can be simulated by the bilinear elastoplastic material. The wheel-rail elastic modulus is $210 \mathrm{Mpa}$, and the yield strength is $650 \mathrm{MPa}$; the strain hardening modulus is $14.879 \mathrm{GPa}$; the material density is $7,800 \mathrm{~kg} / \mathrm{m}^{3}$; and the Poisson's ratio is 0.3 . The friction between wheelsets and rails is defined by Coulomb's friction law, and neither climate nor geographical conditions are considered in the model. The friction coefficient is set to 0.5 to simulate dry and clear friction conditions. Both ends of the broken gap and the wheelsets are of free boundaries, and the corresponding distal rail end is applied with a symmetric constraint.

The interaction and impact between wheelsets and rails can be solved by the surface-to-surface contact algorithm based on the penalty function [24, 25]. For an arbitrary master wheel node $N_{\mathrm{r}}$, the slave wheel node $N_{\mathrm{w}}$ which is closed to the master wheel node $N_{\mathrm{r}}$ can be searched first. If the slave wheel node $N_{\mathrm{w}}$ and master rail node $N_{\mathrm{r}}$ do not coincide, the slave wheel node $N_{\mathrm{w}}$ can be shown whether it lies in one of the segments $S_{l}$ when it crosses the main surface via the following equation:

$\left(s_{i} \times s\right)$

$$
\cdot\left(s_{i} \times s_{i+1}\right)>0 \quad\left(s_{i} \times s\right) \cdot\left(s \times s_{i+1}\right)>0 \quad i=1,2,3,4,
$$

where $s_{i}$ and $s_{i+1}$ represent the vectors along the edges of segment and point outwards from $N_{\mathrm{m}} ; s$ represents the projection of the vector from $N_{\mathrm{m}}$ to $N_{\mathrm{w}}$. Based on the two equations and Newton-Raphson iterations, the normal contact force vector $f_{\mathrm{cN}}$ can be obtained, which is proportional to the penetration as follows:

$l=\boldsymbol{n}_{i} \cdot\left[\boldsymbol{t}-\boldsymbol{r}\left(\eta_{\mathrm{c}}, \theta_{\mathrm{c}}\right)\right]<0$,

$\boldsymbol{f}_{\mathrm{cN}}=-l k \boldsymbol{n}_{i}$,

where $\boldsymbol{r}\left(\eta_{\mathrm{c}}, \theta_{\mathrm{c}}\right)$ is the master segment; $\boldsymbol{t}$ is the vector to the salve wheel node $N_{\mathrm{w}} ; \boldsymbol{n}_{i}$ is a unit outwardly normal to a boundary element on $\Gamma, \boldsymbol{n}_{i}=\left(\frac{\partial r}{\partial \eta} \times \frac{\partial r}{\partial \theta}\right) /\left|\frac{\partial r}{\partial \eta} \times \frac{\partial r}{\partial \theta}\right| ; k$ is the penalty contact stiffness $k=f_{\mathrm{SI}} K A^{2} / V$, in which $K$ is the bulk modulus, $V$ is the element volume, $A$ is the area face of the segment and $f_{\mathrm{SI}}$ is the scale factor for the penalty contact stiffness. The equivalent contact force distributed on the four main nodes of the master segment can be obtained as follows:

$\boldsymbol{f}_{j m}=-\phi_{j}\left(\eta_{\mathrm{c}}, \theta_{\mathrm{c}}\right) \boldsymbol{f}_{\mathrm{cN}}$,

where $-\phi_{j}\left(\eta_{\mathrm{c}}, \theta_{\mathrm{c}}\right)$ is the value of the two-dimensional shape function at the contact point, and $\sum_{j=1}^{4} \phi_{j}\left(\eta_{\mathrm{c}}, \theta_{\mathrm{c}}\right)=1$; The Coulomb friction law is applied to solve the tangential contact between wheel and rail:

$f_{\text {bound }}^{t}=\mu\left|\boldsymbol{f}_{\mathrm{cN}}^{t}\right|$,

$\boldsymbol{f}_{\mathrm{cT}}^{t+1}=\left\{\begin{array}{ll}\boldsymbol{f}_{\mathrm{cT}}^{t}-k \Delta \boldsymbol{e} & \boldsymbol{f}_{\mathrm{cT}}^{t}-k \Delta \boldsymbol{e}<\mu\left|\boldsymbol{f}_{\mathrm{cN}}^{t+1}\right| \\ \frac{f_{\mathrm{bound}}^{t+1} \times \boldsymbol{f}}{\left|\boldsymbol{f}_{\mathrm{cT}}^{t}-k \Delta \boldsymbol{e}\right|} & \boldsymbol{f}_{\mathrm{cT}}^{t}-k \Delta \boldsymbol{e}>\mu\left|\boldsymbol{f}_{\mathrm{cN}}^{t+1}\right|\end{array}\right.$,

$\boldsymbol{f}_{\text {con }}^{t}=\sum_{M=1}^{m}\left(\int_{\Gamma_{c, e}} \boldsymbol{N}^{\mathrm{T}}\left(\boldsymbol{f}_{\mathrm{cN}}^{t}+\boldsymbol{f}_{\mathrm{cT}}^{t}\right) \mathrm{d} \Gamma\right)^{M}$,

where $f$ is the tangential contact force of the node at time step $t+1$, and $\boldsymbol{f}=\boldsymbol{f}_{\mathrm{cT}}^{t}-k \Delta \boldsymbol{e} ; \boldsymbol{f}_{\mathrm{cT}}^{t}$ is the tangential contact force at time $t ; \Delta e$ is the increment along the slave node on rail surface; $k$ is the penalty contact stiffness; $f_{\text {bound }}^{t}$ is the traction bound at time $t ; \boldsymbol{f}_{\text {con }}^{t}$ is the contact force vector; $\boldsymbol{N}^{\mathrm{T}}$ is the transpose of the shape matrix constructed by the shape functions; $\mu$ is the friction coefficient. 
After the establishment of the explicit finite element model, the typical complex calculation process mainly consists of two parts: the implicit static calculation and the explicit dynamic calculation. First, the wheelset is set to stand still on the rail, and then, the gravity acceleration is applied to calculate the displacement field of the wheel-rail system (static implicit solution) under static wheel load. Afterward, the obtained nodal displacement of the model is taken as the initial state of the wheel-rail system for the explicit calculation, then the initial forward speed $(250 \mathrm{~km} / \mathrm{P})$ are prescribed on the nodes of the wheel and vehicle to simulate the forward motion, and the angular speed is set on the nodes of the wheel to rotate around the wheel axle, which equals to the quotient of forward velocity and wheel rolling radius. The frictional rolling contact solutions and dynamic response of wheel-rail impact (transient explicit solution) are derived based on the explicit time integration algorithm. Due to the differences of integration methods and motion states in the above twostep calculation process, the initial state of the dynamic analysis should be processed by stress initialization according to the static implicit solution; for this purpose, an unreal dynamic disturbance will be introduced. In order to avoid the effect of the initial disturbance on the accuracy of simulation results, a $1.2 \mathrm{~m}$ long section of dynamic relaxation region shall be introduced to ensure that the energy of the initial disturbance is consumed when the wheel-rail contact patch is located at the broken gap (Fig. 5).

Before wheel-rail impact at the gap, the vertical wheelrail contact force equals to the wheel load, and the wheel and rail will be in a steady contact status. Thus, the frictional rolling contact solutions in contact patch can be validated by comparing the results from CONTACT and Hertz, as shown in Table 1, where the simulation results of the explicit finite element method are consistent with those obtained from CONTACT and Hertz.

\section{Simulation results}

In this section, the three-dimensional explicit finite element model is used to simulate the wheel-rail interaction during the passage of wheel over the gap under actual operation conditions; then, the stress mechanism of the rails and the

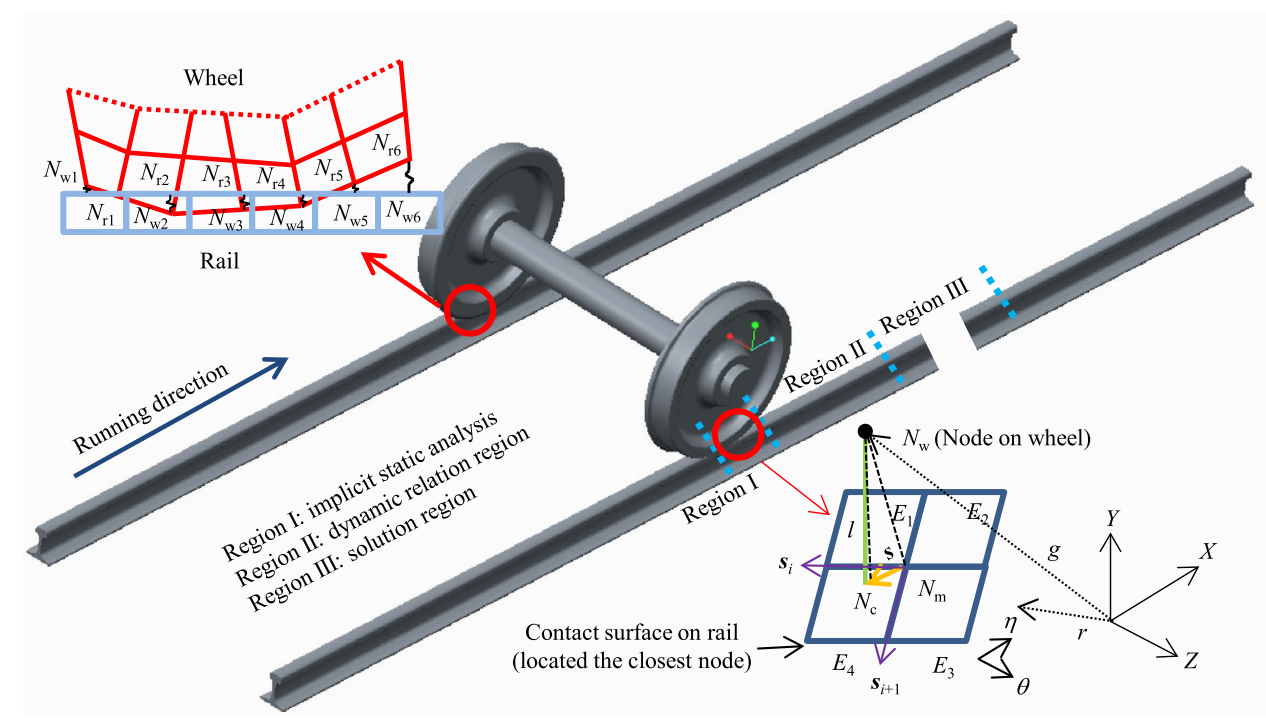

Fig. 5 Sketch of rail subjected to broken gap

Table 1 Comparison of the simulated results

\begin{tabular}{|c|c|c|c|c|c|}
\hline \multirow[t]{2}{*}{ Approach } & \multicolumn{3}{|l|}{ Contact patch } & \multicolumn{2}{|l|}{ Maximum stress } \\
\hline & Major semi-axis (mm) & Minor semi-axis (mm) & Area $\left(\mathrm{mm}^{2}\right)$ & Vertical (MPa) & Shear (MPa) \\
\hline Explicit FE & 7.31 & 5.62 & 129.06 & 834.5 & 224.3 \\
\hline CONTACT & 7.35 & 5.51 & 127.23 & 848.1 & 234.1 \\
\hline Difference w.r.t. CONTACT & 0.04 & -0.11 & -1.83 & 13.6 & 9.8 \\
\hline Hertz & 7.40 & 5.8 & 134.83 & 857.1 & - \\
\hline Difference w.r.t. Hertz & 0.09 & 0.18 & 5.77 & 22.6 & - \\
\hline
\end{tabular}



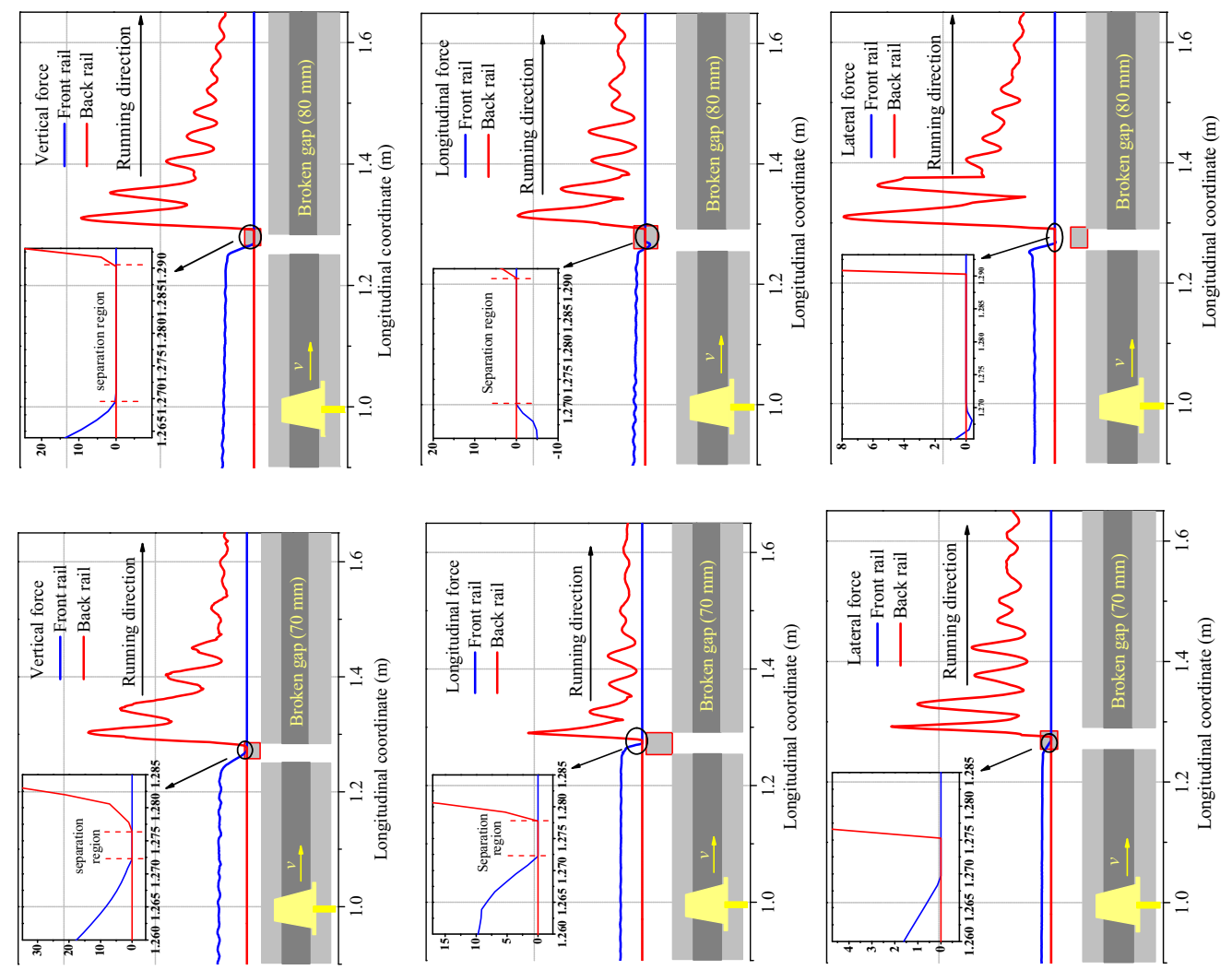

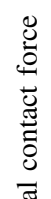
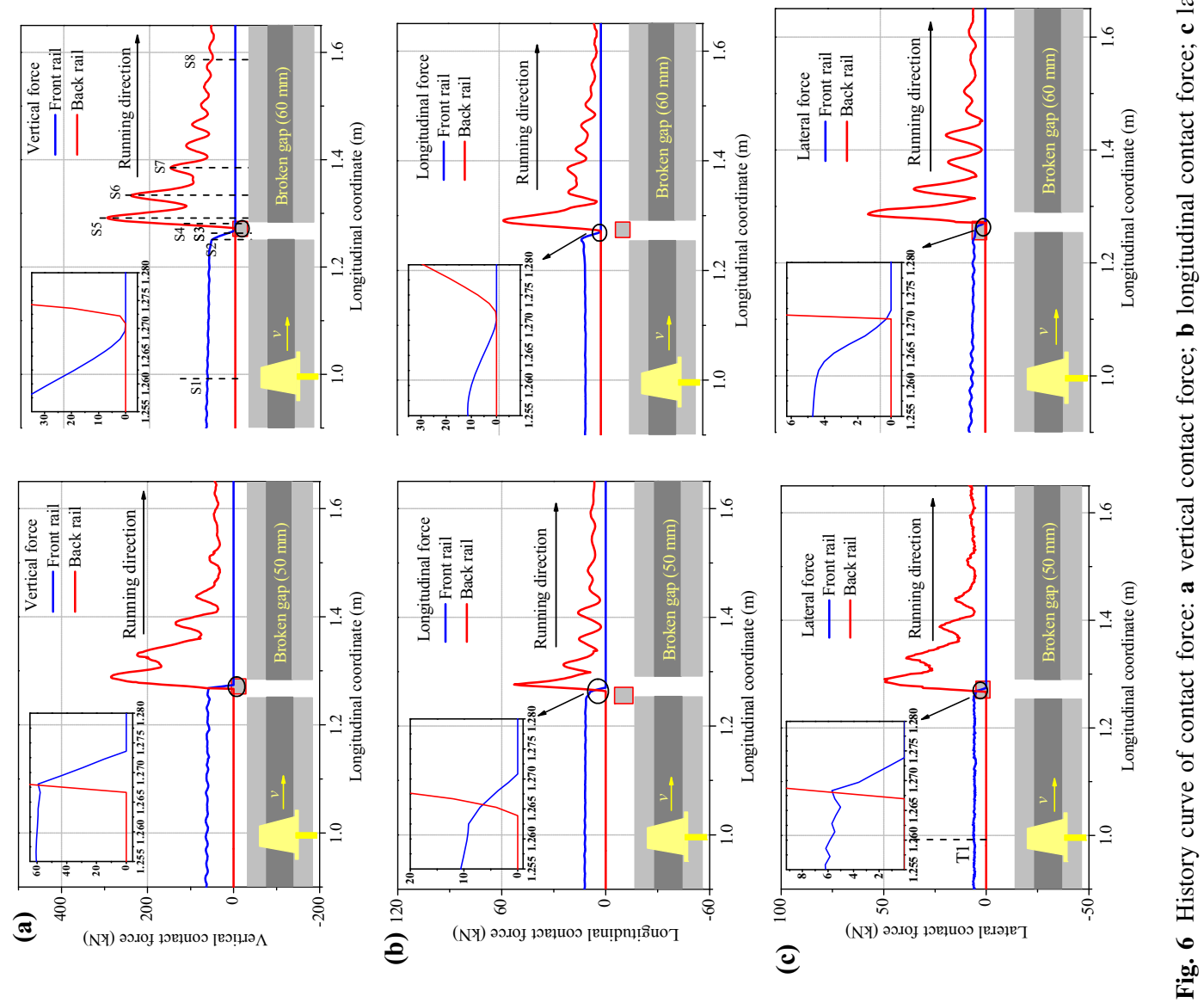


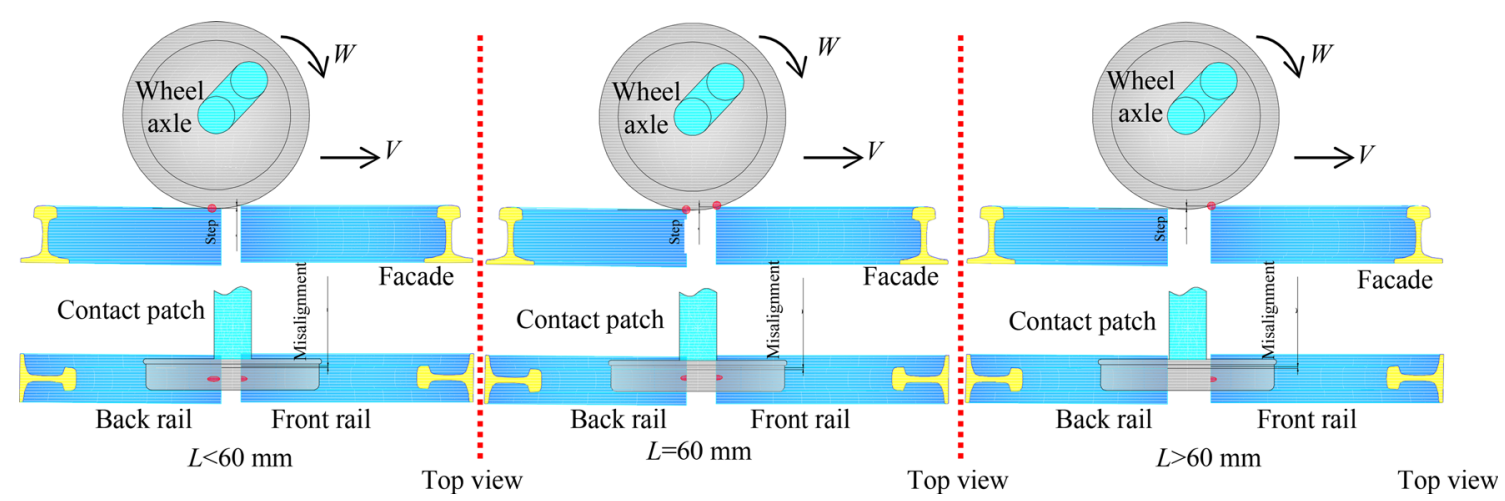

Fig. 7 Contact behavior between the wheel and rail with different gap lengths

contact force evolution are analyzed, and the possibility of secondary fracture to the rails in case of the steel rail fracture is explored.

\subsection{Wheel-rail dynamic response}

Figure 6 shows the time-history curves of the wheel-rail contact forces when wheels roll through the rail with different broken gap lengths $(50,60,70$ and $80 \mathrm{~mm})$, and the simulation results include vertical, lateral and longitudinal contact force.

As indicated in Fig. 6, the front rail and back rail can be regarded as the cantilever beam, when the wheel-rail contact patch is located on front rail, the rail end will sink under the effect of wheel load, thus forming a height difference between the top surface of the back rail and front rail; when the wheelset impacts the back rail, due to the loss of vertical bending stiffness, the vertical wheel-rail contact force will gradually decrease along the front rail. In addition, the wheel-rail interaction during impact between solids inherently consists of high-frequency shock and vibration; hence, the back rail will be subjected to enormous high-frequency impact force. The maximum vertical wheel-rail force during impact can reach up to $308.3 \mathrm{kN}$, which is about 4 times that of the static wheel load and occurs about $0.2 \mathrm{~ms}$ after the impact, namely about $13 \mathrm{~mm}$ away from the back rail end at the broken gap. When the wheels continue to roll forward, due to the release of track elastic energy, the wheels will continue to impact the back rail. The wheel-rail contact force will fluctuate with time and gradually become stable under the influence of fastener damping and structural damping.

The evolution law of the lateral and longitudinal contact forces is similar to that of vertical force. Taking the $60 \mathrm{~mm}$ length of gap as example, the maximum values of the longitudinal force and lateral force during the impact are 58.4 and $57.1 \mathrm{kN}$, respectively. Due to the freely constrained end of front rail at the broken gap, the lateral displacement of front rail end will increase under the action of the lateral impact force, which causes a certain degree of deviation between the center line of the rail and the running direction of the wheelset. Therefore, the misalignment between longitudinal axle of the front rail and back rail will increase the lateral creepage. Since the wheel-rail contact patch is not located at the center of the rail, the lateral force decays slower than the vertical force, and the lateral contact force will decrease to zero in a longer time, resulting in a relatively longer time of detachment between the wheel and rail.

As shown Fig. 7 shows, when the length of gap is less than $60 \mathrm{~mm}$, the wheel-rail contact patch is located in front of the front rail end. During the violent impact between the wheel and back rails, the dynamic response of wheel-rail impact is relatively smaller due to the supporting effect of the front rail compared with the gap exceeding $60 \mathrm{~mm}$. When the gap length equals to $60 \mathrm{~mm}$, the wheel will continue rolling forward, and the contact patch between wheelset and front rail will move forward to the end of the rail, where the wheel is in contact with back rail and front rail simultaneously, and the bending of front rail will be intensified under the influence of impact, leading to bigger step values. Therefore, the dynamic response of wheel-rail impact will be intensified. When the gap length exceeds $60 \mathrm{~mm}$, the wheel is in contact with the back rail, the wheel will detach from the front rail, and then, the wheel will impact the back rail under the effect of gravity. As there is no supporting effect of the front rail during the impact, the dynamic response of wheel-rail impact will be aggravated, and the increase velocity is far greater than the one at the moment when the length of gap is less than $60 \mathrm{~mm}$. In addition, when the gap length exceeds $60 \mathrm{~mm}$, the sharp corner of the back rail end will be subjected to the entirely wheel dynamic loading independently, which is very easy to cause the spall of sharp corner and the unexpected expansion of the length of gap; further the derailment or overturning of the vehicle is easily to happen. Therefore, 
the $60 \mathrm{~mm}$ length of gap can be regarded as a special condition that distinguishes the contact behavior during the passage of wheel over the gap.

As the rail fracture seriously threatens the running safety of vehicles, it is necessary to analyze the derailment coefficient, wheel unloading rate, step value and lateral displacement difference between the back rail and front rail, which are closely associated with the running safety of vehicle.

As seen from Fig. 8, when the gap length exceeds $60 \mathrm{~mm}$, the wheelset will detach from the rail during the impact, the derailment coefficient is considered to be exceeding the limit because the vertical contact force at this instant is 0 ; therefore, the derailment coefficient equals to zero at the moment of wheel-rail separation. When the gap length is less than $60 \mathrm{~mm}$, the wheel will keep in contact with the back rail and front rail, and thus, the derailment coefficient is greater than zero. The derailment coefficient increases as the gap length, especially when the gap length exceeds $60 \mathrm{~mm}$, the growth rate of maximum derailment coefficient increases significantly due to the change of wheel-rail contact behavior at broken gap. In addition, the maximum value of derailment coefficient corresponding to the $80 \mathrm{~mm}$ gap length is 0.268 , which is less than the threshold specified in [7]. However, due to the violent impact induced by gap, the maximum wheel unloading rate corresponding to the $80 \mathrm{~mm}$ gap length can reach up to 0.754 , which exceeds the threshold of the safety index [7] and threatens the running safety of the vehicle. When the gap length exceeds $60 \mathrm{~mm}$, due to the change of wheel-rail contact behavior at broken gap, the dynamic response of the wheel-rail impact will be intensified, and the wheel unloading rate will exceed the threshold [7] (Fig. 9).

The step height and lateral displacement difference between the front rail and back rail are two main factors

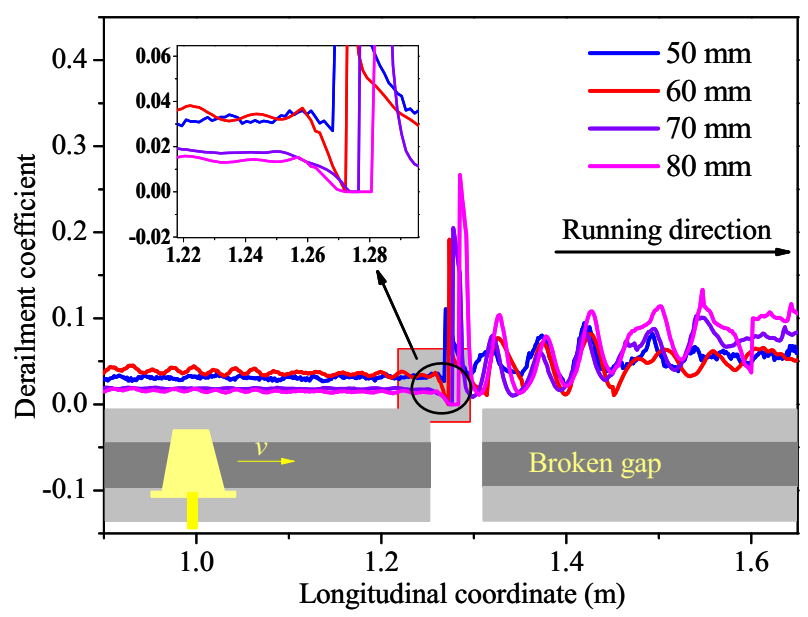

Fig. 8 Distribution of derailment coefficient influencing the dynamic wheel-rail impact and running safety of vehicle. The front rail is sunk by the action of dynamic vertical wheel-rail contact force, forming a height difference with the top surface of the back rail. The height difference is the first major affected factor, also known as step. If the step value is relatively large, the wheel will impact the back rail, leading to violent dynamic response of the wheel-rail interaction. According to Fig. 10a, the value of step height is up to $2.9 \mathrm{~mm}$. Moreover, due to the flexural rigidity of rails, the vertical displacement of the back rail has not yet reached the maximum when the vertical contact force reaches the maximum. The right rail is broken while the left rail is non-damaged, which means that the difference of vertical disturbance degree between the left and right rails will cause the tilting of car body, leading to violent lateral wheel-rail contact force. Moreover, the lateral force will cause the lateral displacement of the wheel and rail. If it is too large, the flange may consequently climb on rails when the contact patch is transmitted from the front rail to back rail, thereby causing the train to derail and threatening the driving safety. Thus, the second major affected factor is the lateral displacement difference between the front and back rails. As shown in Fig. 10b, due to the freely restrained end of the front rail at the broken gap, the maximum lateral displacement difference of $2.13 \mathrm{~mm}$ between the front and back rails occurs at the front rail end, which is less than the measured limit [7].

The step and lateral displacement difference under different gap lengths is shown in Fig. 11, where the step and lateral displacement difference can be regarded as irregularities to some extent, which can intensify the wheel-rail impact and threaten the running safety of vehicle. Especially when the gap length exceeds $60 \mathrm{~mm}$, the growth rate of the step, vertical displacement and lateral displacement is greater than that in the case of the gap length being less than $60 \mathrm{~mm}$. The dynamic response of wheel-rail

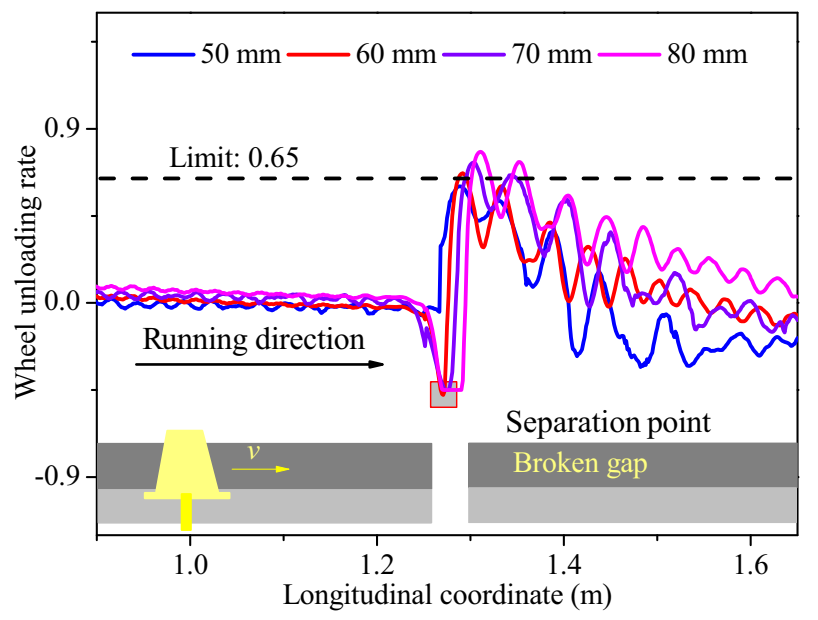

Fig. 9 Distribution of wheel unloading rate 
(a)

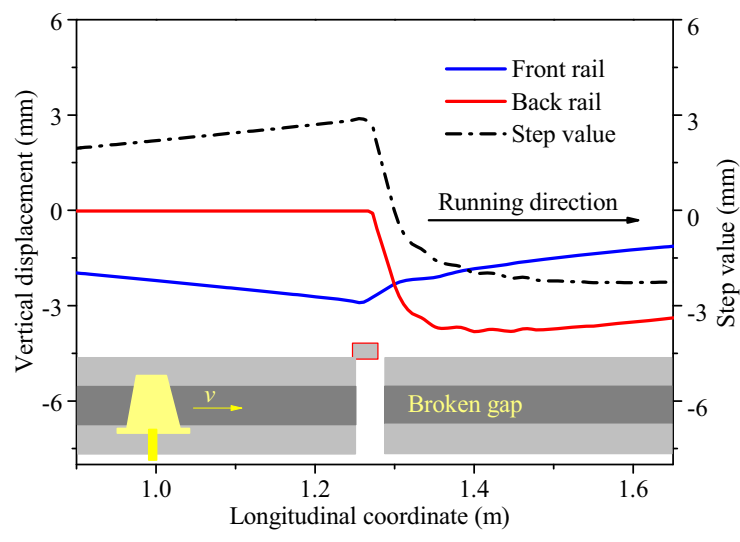

(b)

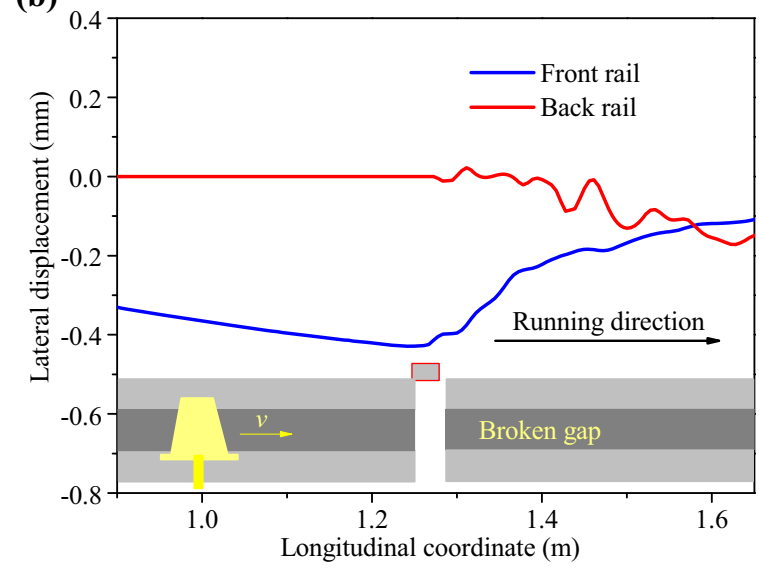

Fig. 10 History curves of wheel displacement $(60 \mathrm{~mm})$ : a vertical displacement; b lateral displacement

(a)

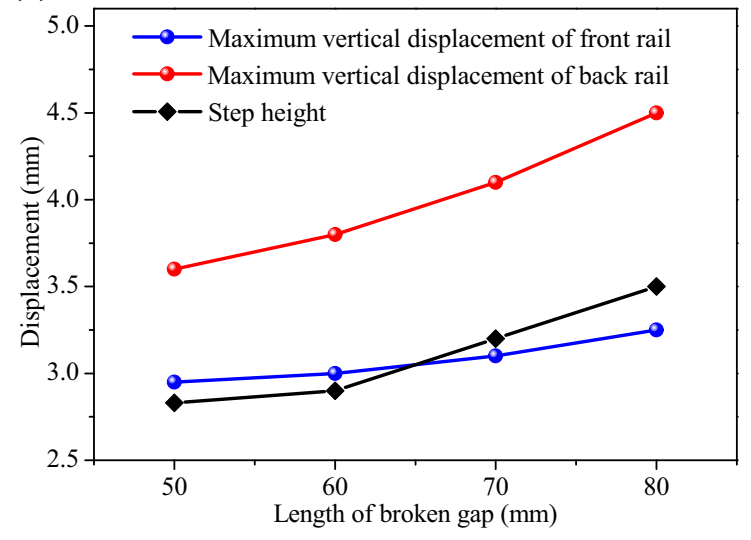

(b)



Fig. 11 Maximum step and rail displacements under different gap lengths: a vertical displacement and step height; b lateral displacement

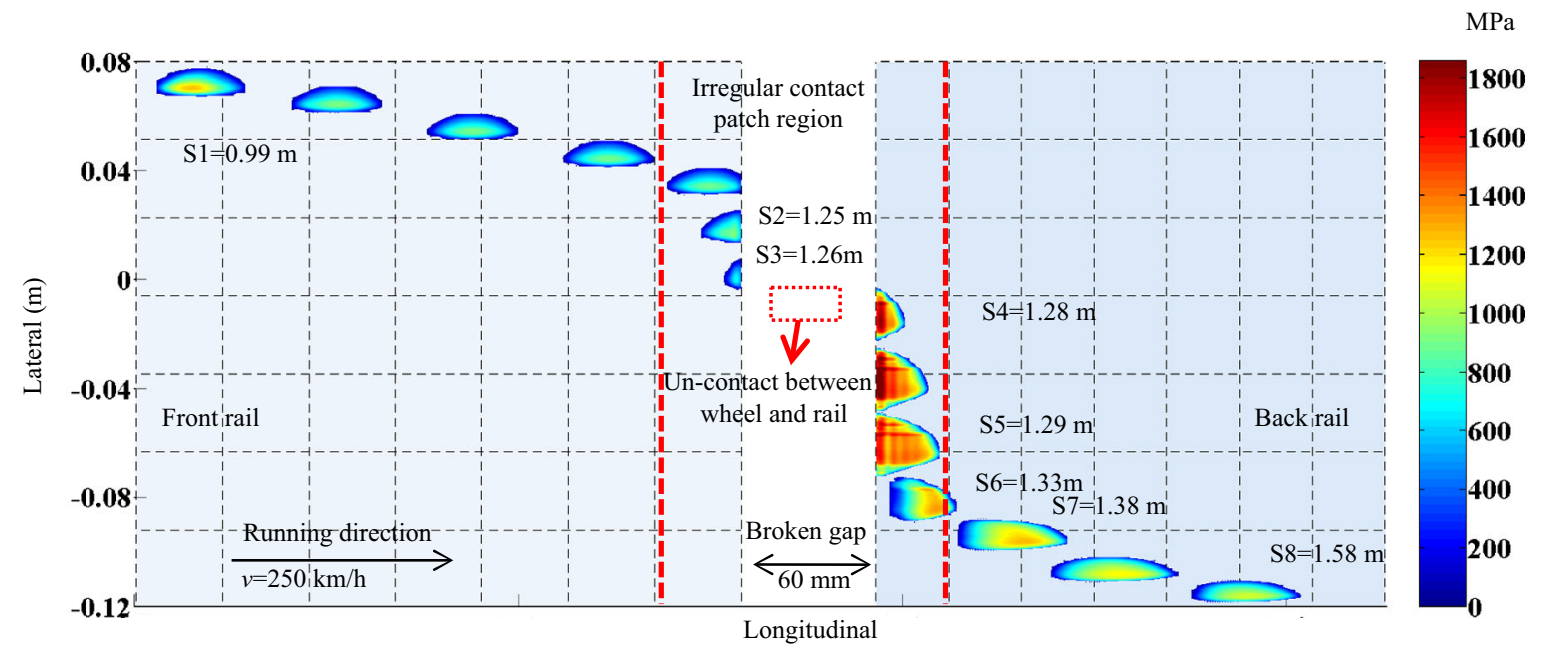

Fig. 12 Surface normal pressure distribution $(60 \mathrm{~mm})$ 
interaction will increase with the gap length, leading to the violent dynamic response of wheel-rail interaction, and the significantly increased risk of vehicle derailment.

\subsection{Evolution of frictional rolling contact behavior}

An accurate stress analysis is the other key factor to recognize the rail secondary fracture and the wheel/rail contact behavior at broken gap. Eight typical instants (S1-S8) are selected for analysis, including the instant with the maximum vertical wheel-rail force (Fig. 6). In order to determine whether the rail will suffer from the secondary fracture, the split Hopkinson pressure bar (SHPB) and the split Hopkinson tensile bar (SHB) [18] are used to obtain evaluation indexes: the ultimate tensile strength of U71Mn steel is $1188 \mathrm{Mpa}$ and the yield strength is $650 \mathrm{Mpa}$. For the ease of description, the following figures all take the $60 \mathrm{~mm}$ length of gap as a display objective, and finally the maximum objective values corresponding to different gap lengths are summarized.

Figure 12 illustrates the magnitude and distribution of contact stress along the longitudinal axle of the rail. The contact stress before impact is relatively small and slowly decreases due to the deflexibility of front rail (S1-S3). Then, the contact stress increases rapidly after the wheelset impacts the back rail, reaches the maximum value in about $0.2 \mathrm{~ms}$ after the occurrence of impact. After the impact, the contact stress will rapidly decrease under the effect of structural damping and fasteners damping. Furthermore, when the contact patch is located near the end of the front rail at the broken gap, the shape of the contact patch changes from ellipse to semi-ellipse (S4) due to the influence of broken gap, and the geometric area of contact patch on front rail gradually decreases to zero. When the wheelset impacts the back rail, the end of the back rail will withstand severe contact stress (S5), and its sharp corners will be subjected to the maximum stress. Besides, when the wheelset just leaves the end of the back rail, the vertical free section of the back rail at the broken gap is bent downward under the dynamic impact loading. Because the flexural rigidity of the broken rail is much smaller than that of the ordinary rail, the bending deformation of the back rail is relatively large, leading to a decrease in the contact stiffness and a reduction size of front contact patch (S6S7). When the wheel-rail contact patch is far away from the rail end, the contact patch will return to its elliptical shape (S8).

Figure 13 demonstrates the magnitude and distribution of the normal stress along the lateral-vertical section of the rails at eight typical moments. Specifically, (a)-(c) show the contact patch which are located at the front rail, because the vertical wheel-rail force continues to decrease along the longitudinal direction of the front rail, and the normal contact stress is continuously reduced during this period; (d)-(h) show the contact patch which is located at the back rail. During the impact, the normal contact stress reaches the maximum in a short time, and then, the contact stress will slowly decrease after the impact. The maximum normal contact stress is located at the rail surface with a value up to 1,953 MPa, and it decreases sharply with the increase in the depth. After the impact, the wheel-rail normal stress is of crescent-shaped distribution; when the wheel continues rolling forward, the crescent-shaped stress will gradually return to the size as Fig. 13a. Compared with the case where the wheel-rail contact patch is located at the front rail, the stress is substantially increased.

Figure 14 indicates the distribution of the surface shear stress along the longitudinal axle of the rail. When the contact patch is located at the front rail, the maximum shear stress occurs in the rear of the wheel-rail contact patch due to the influence of longitudinal contact force (S1-S3). After the impact, the sharp corner of the end of the back rail is used as the pivot point during the passage of wheel over broken rail; therefore, the maximum shear

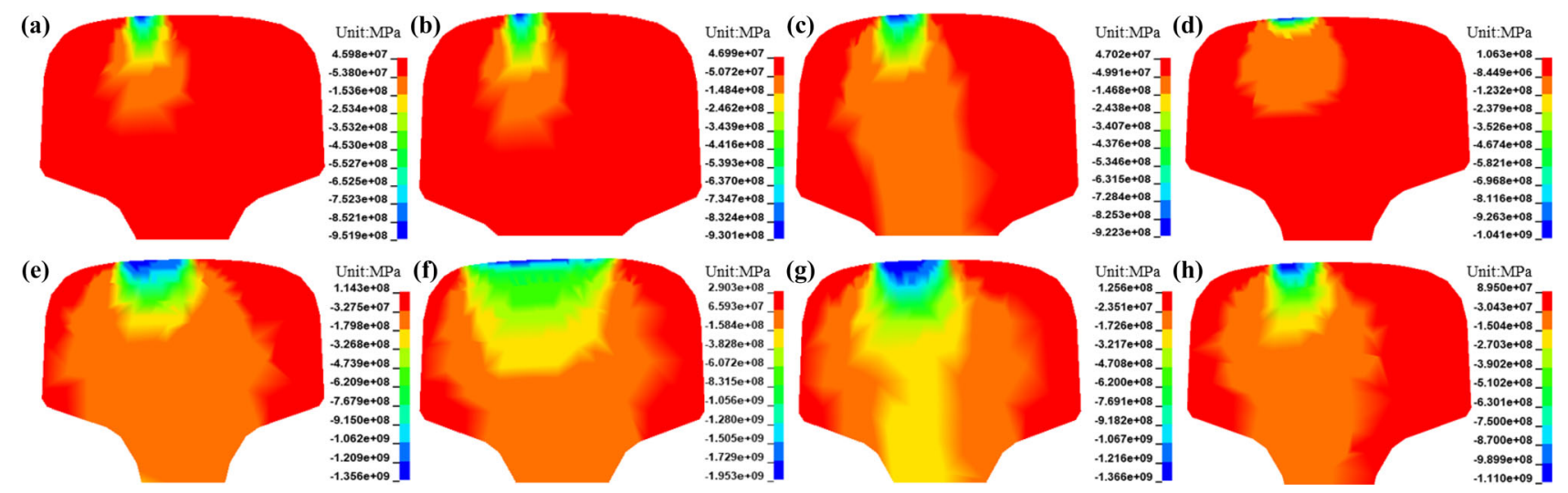

Fig. 13 Normal stress distribution at lateral-vertical Sect. $(60 \mathrm{~mm})$ for S1-S8 (a-h) 


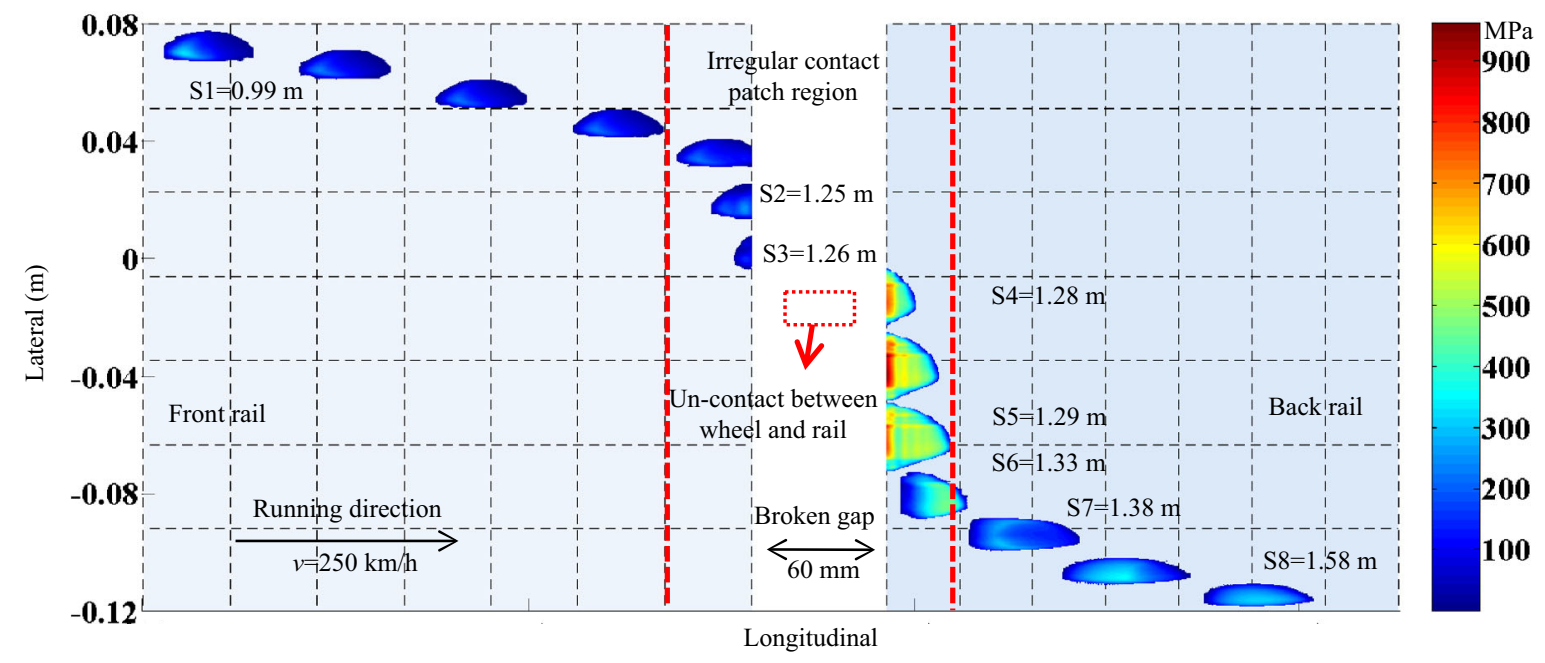

Fig. 14 Surface shear pressure distribution $(60 \mathrm{~mm})$
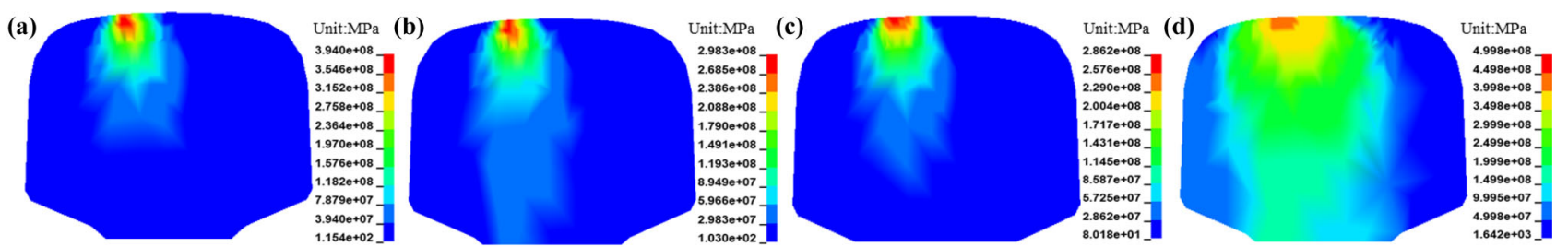

(e)

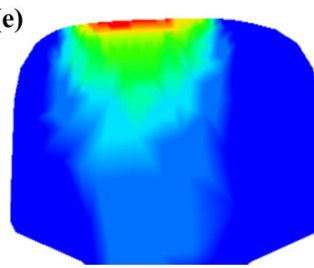

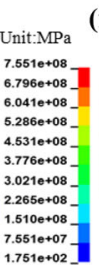

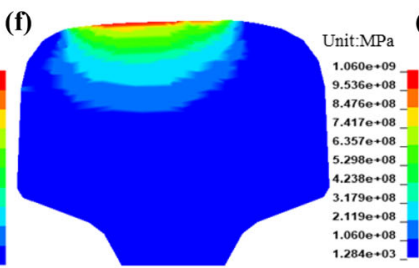

(g)

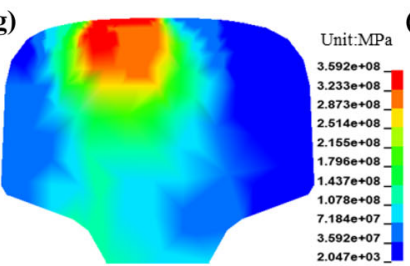

(h)

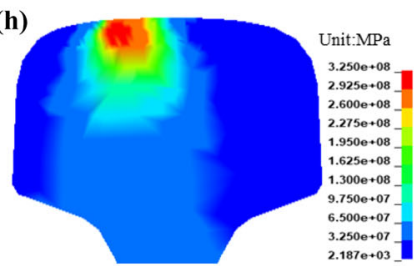

Fig. 15 Subsurface shear stress distribution $(60 \mathrm{~mm})$ for S1-S8 $(\mathbf{a}-\mathbf{h})$

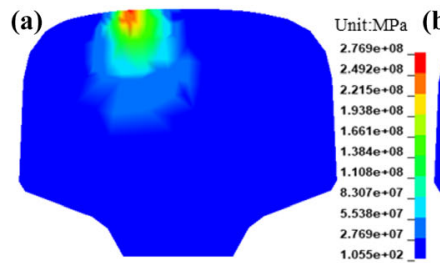

(e)

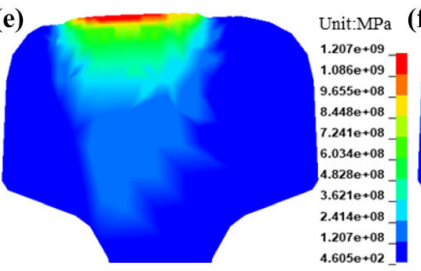

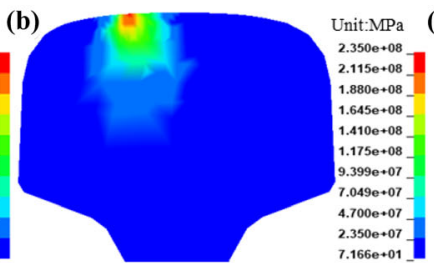

(f)

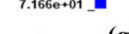

Unit:MPa (g)

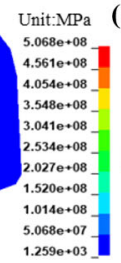

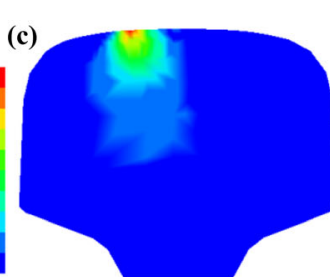
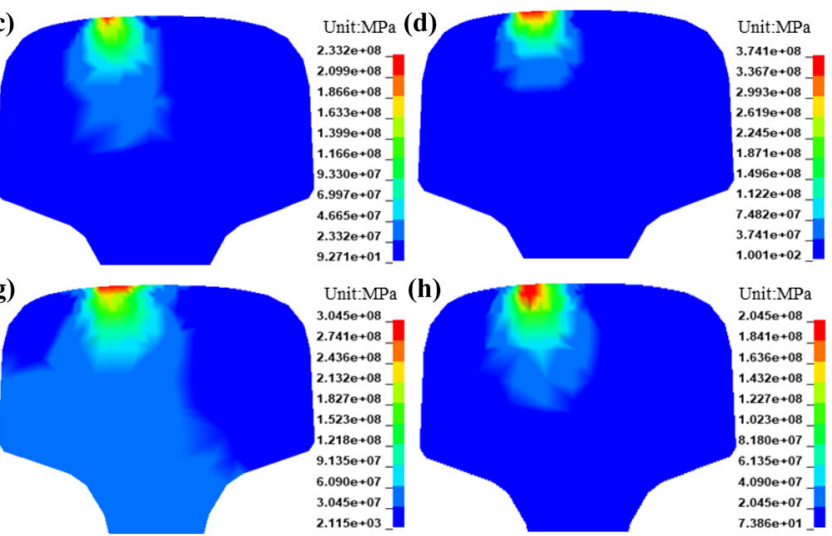

Fig. 16 Subsurface tensile stress distribution $(60 \mathrm{~mm})$ for $\mathrm{S} 1-\mathrm{S} 8(\mathbf{a}-\mathbf{h})$

stress is concentrated on the sharp corner of rail end (S4S5). Similar to the distribution rules of normal contact stress, because the vertical flexural rigidity at the broken rail is much smaller than that of the ordinary rail, the back rail under the dynamic impact load will undergo large bending deflection, thereby resulting in the non-elliptical distribution of shear stress (S6-S7), and the location of the maximum shear stress will gradually move to the rear of 
the contact patch. When the wheel-rail contact patch is away from the rail end, the distribution of shear stress returns to an elliptical shape, and it will remain stable when the shear stress gradually drops to a certain value (S8).

Figure 15 shows the magnitude and distribution of the maximum shear stress along the lateral-vertical section of the rails at eight typical moments. Similarly, (a)-(c) show the contact patch which are located at the front rail; the rail bends along the longitudinal direction and activate an effect like unloading, the shear stress continues to decrease, and the maximum shear stress before impact is located at $2.2 \mathrm{~mm}$ below the rail surface. (d)-(h) show the contact patch which are located at the back rail, the value of the maximum shear stress is significantly increased due to the wheel-rail impact, which can reach up to $1060 \mathrm{MPa}$, and the impact causes the maximum shear stress to move to the rail surface. Under the coupled effect of the normal dynamic impact load, the crescent-shaped distribution can be observed on the lateral-vertical section of rails. When the wheelset is away from the broken gap, the value of the maximum shear stress gradually decreases and returns back below the rail surface.

Based on the first strength theory, the first principal stress can be equivalent to the maximum tensile stress, and the rail secondary fracture can be predicted by comparison of the threshold of first principal stress and the ultimate tensile strength. Figure 16 shows the distribution of the first principal stress along the lateral-vertical plane of steel rails at eight typical moments.

Specifically, (a)-(c) show the contact patch which are located at the back rail, and the tensile stress continues to decrease along the longitudinal direction of the front rail. (d)-(h) show the contact patch which is located at the back rail. Due to the violent wheel-rail impact, the maximum tensile stress of the rail surface is increased with a crescent shape. The value of the maximum tensile stress can reach up tp 1,207 MPa (the gap length equals to $60 \mathrm{~mm}$ ), slightly higher than the ultimate tensile strength of the rail material; if the gap length exceeds $60 \mathrm{~mm}$, the violent force induced by impact may cause rail secondary fracture. In addition, when the gap length exceeds $60 \mathrm{~mm}$, the maximum contact stress, shear stress and maximum tensile stress are all located at the sharp corners of the back rail end during impact, and the distribution of tensile stress is a long and

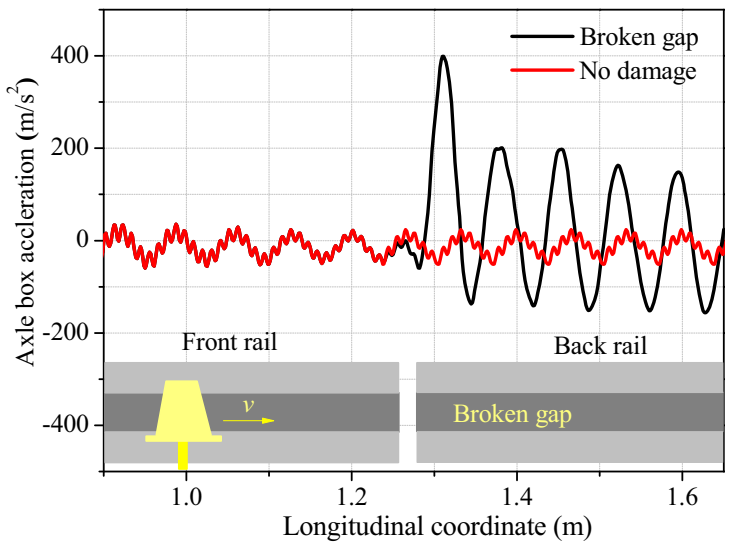

Fig. 17 Time history curve of axle acceleration $(60 \mathrm{~mm})$

narrow crescent. Therefore if the rail fracture cannot be found in time, the wheels will repeatedly hit the sharp corners at the rail end, which may cause rail secondary fracture and threaten the running safety of the vehicle.

As shown in Table 2, the contact stress and shear stress as well as the tensile stress are all positively correlated with the length of broken gap. As the gap length exceeds the $60 \mathrm{~mm}$, the growth rate of the stress increase much faster, the tensile stress corresponding to $70 \mathrm{~mm}$ length of broken gap is slightly higher than the ultimate tensile strength of the rail material. If the length of broken gap is less than $60 \mathrm{~mm}$, the value of stress will be slightly lower than the ultimate failure strength, and the rail secondary fracture will not occur immediately. If the rail fracture is not detected timely, the occurrence of secondary fracture will be further intensified. Therefore, it is suggested that the length of gap should be controlled within $60 \mathrm{~mm}$ from the angle of the stress and rail secondary fracture.

\subsection{Axle acceleration analysis}

Based on the analysis above, broken gaps are a type of unpredictable damage to high-speed railway track. Some parts of the rail fracture cannot be detected by real-time safety system, for instance the turnout. If maintenance is not conducted timely, the enormous impact load will be excited when the wheelset passes through the broken gap, which may cause rail secondary fracture. As the dynamic response of wheel-rail impact between solids inherently

Table 2 Maximum stresses at different gap lengths

\begin{tabular}{llrr}
\hline Length of broken gap $(\mathrm{mm})$ & Contact stress (MPa) & Shear stress (MPa) & Tensile stress (MPa) \\
\hline 50 & 1,721 & 891 & 1,040 \\
60 & 1,953 & 1,060 & 1,207 \\
70 & 2,201 & 1,232 & 1,401 \\
80 & 2,445 & 1,454 & 1,673 \\
\hline
\end{tabular}




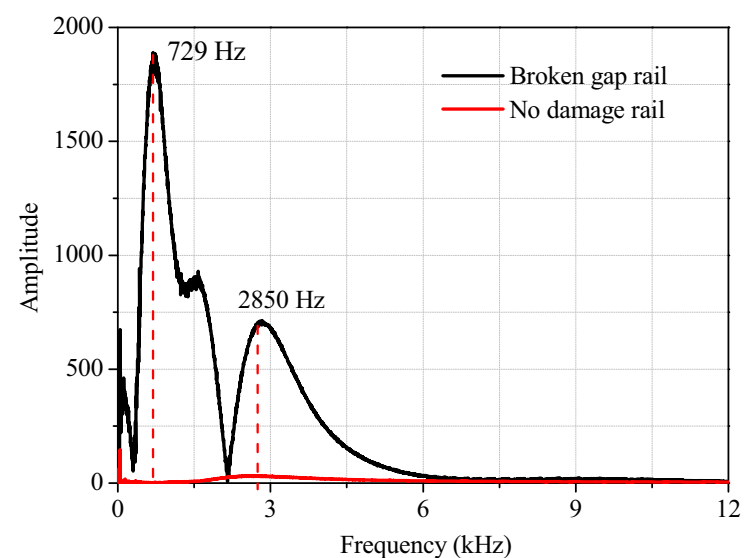

Fig. 18 Frequency domain response (S-transformation) at $60 \mathrm{~mm}$

consists of high-frequency vibration, to develop an insightful understanding of the wheel-rail contact behavior at broken gap, the dynamic response of the wheel-rail impact in frequency domain is investigated.

Figure 17 compares the axle acceleration in frequency domain between the broken gap and undamaged rail. The result is processed by the low-pass filtered method to eliminate the interference of high-frequency noise. The above figure indicates a slight fluctuation in the axle acceleration of wheels in case of no damage, which is caused by the transient contact between wheels and rails. In this segment of signal, the maximum value of the axle

(a)

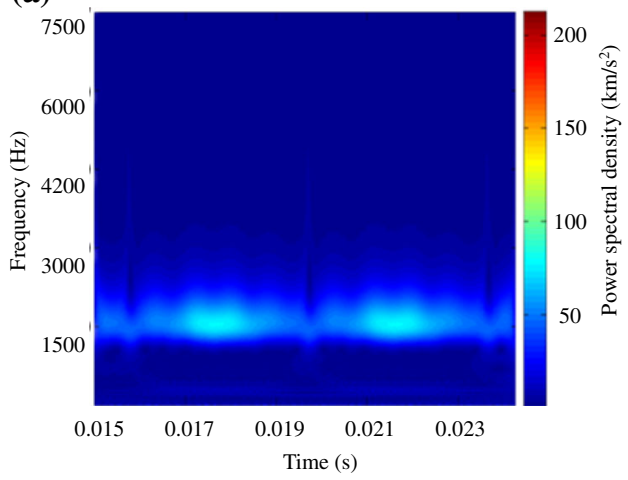

acceleration is $42 \mathrm{~m} / \mathrm{s}^{2}$, and the signal mainly fluctuates between the range of -42 and $30 \mathrm{~m} / \mathrm{s}^{2}$, which is consistent with the experimental results in Ref [26].. The broken gap will evoke more intense amplitude fluctuations in the axle acceleration, the range of axle acceleration fluctuations is between -150 and $400 \mathrm{~m} / \mathrm{s}^{2}$, and its maximum value can reach up to $400 \mathrm{~m} / \mathrm{s}^{2}$. In Fig. 17, the maximum axle acceleration and maximum wheel-rail vertical force are located at 1.315 and $1.293 \mathrm{~m}$, respectively. Therefore, the maximum energy of the axle acceleration mainly occurs after the impact.

Figure 18 is the time-frequency distribution of axle acceleration processed by wavelet transform. In case of non-damaged rails, the energy distribution curve of the axle acceleration is relatively smooth. In the case of a broken gap, the energy of axle acceleration curve is mainly distributed between $404 \mathrm{~Hz}$ and 1,637 Hz (see Fig. 19), which corresponds to the high-frequency impact load caused by the first impact and low frequency excited by the subsequent vibration, respectively. The frequency of the impact excited at the broken gap is relatively high, which is caused by unconstrained end at the broken rails and wheel-rail high-speed impact. The high-frequency load decays quickly under the effect of the inertia force of the rail, and there is no enough time to transmit it to the vehicle and the rail substructure.

As shown in Table 3, it is evident that the axle accelerations caused by the broken gap and non-damaged rails

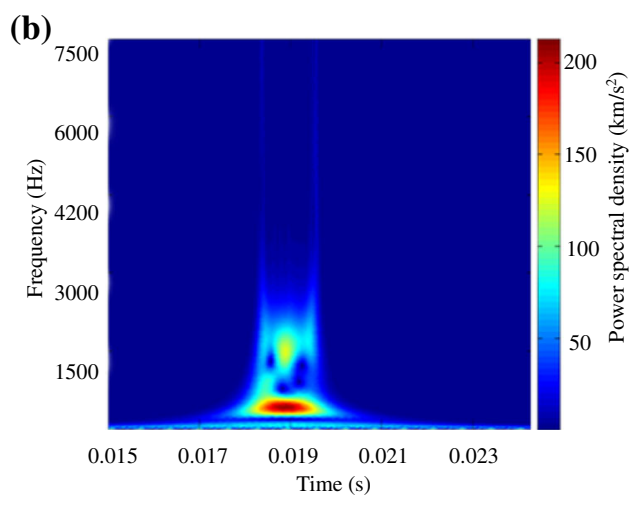

Fig. 19 Time-frequency distribution map of axle acceleration with a non-damage rail and b broken rail at $60 \mathrm{~mm}$ gap

Table 3 Maximum axle acceleration and frequency for different gap lengths

\begin{tabular}{llll}
\hline Length of broken gap $(\mathrm{mm})$ & Axle box acceleration $\left(\mathrm{m} / \mathrm{s}^{2}\right)$ & \multicolumn{2}{l}{ Frequency } \\
\cline { 3 - 4 } & & First shock $(\mathrm{Hz})$ & Subsequent vibration $(\mathrm{Hz})$ \\
\hline 50 & 356.5 & 1,604 & 398 \\
60 & 401.1 & 1,637 & 404 \\
70 & 460.5 & 1,710 & 432 \\
80 & 522.2 & 1,736 & 440 \\
\hline
\end{tabular}


are remarkably different in domains of time and frequency, where the frequency of axle accelerations are concentrated between $1,500 \mathrm{~Hz}$ and 1,800 Hz. Besides, given the influence of high-frequency load, the surface of rail end near the broken gap is a relatively dangerous region.

The wheel will vibrate more violently with the gap length increasing. The different lengths correspond to the different values of the frequency of first impact and subsequent vibrations, and the amplitude of axle box acceleration is positively correlated with the length of broken gap. However, the frequency characteristic has no connection with the length of broken gap. During the wheel passage over gaps. The frequencies corresponding to the peak value of the amplitude under different gap lengths are consistent, which are mainly concentrated near the $404 \mathrm{~Hz}$ and $1,637 \mathrm{~Hz}$ as shown in Table 3. In addition, it is evident that the axle accelerations caused by the broken gap and non-damaged rails are remarkably different in domains of time and frequency, which is probably related to the reduction of the vertical structural stiffness at the gap. This is similar to the free end of a cantilever beam.

\section{Conclusions}

Aiming at the effect of rail fracture on the wheel-rail contact behavior and running safety of trains on high-speed railways, we simulate the process when the wheels impact the broken rail on the basis of the three-dimensional explicit finite element model, investigate the rail stress mechanism and vibration rule of the wheel at the broken gap and reach the following conclusions from the above analysis:

1. The maximum wheel-rail contact force caused by the broken gap can be 4-5 times that of the static wheel load. When the gap length exceeds $60 \mathrm{~mm}$, the derailment coefficient is smaller than the standard value, but the wheel unloading rate is higher than the threshold. The growth rate of step and lateral displacement difference between the front rail and back rail increase faster when the gap length exceeds $60 \mathrm{~mm}$.

2. The geometrical shape of the contact patch evolves along the rail during the impact process. The shape is semi-elliptical on the rail surface and crescent-shaped along the depth. Therefore, the sharp corner of the back rail end is the weaker part under the wheel impact loading.

3. Broken gaps can significantly increase the stress field on the rail. Under the influence of the impact, the maximum contact stress and shear stress are located at the end of the back rail, which occurs at $0.2 \mathrm{~ms}$ after the impact. When the gap length exceeds $60 \mathrm{~mm}$, the maximum shear stress and the maximum tensile stress borne by the rail are slightly more than the ultimate breaking strength, and the rail secondary fracture may occur.

4. The frequency domain energy excited by the broken gap is mainly concentrated between 1,500 and $1800 \mathrm{~Hz}$, and the difference of frequency value between the broken gap and non-damage rail is relative large.

5. The limited broken gap for high-speed railways should be less than $60 \mathrm{~mm}$, if the length exceeds the $60 \mathrm{~mm}$ (LMA profile and at $250 \mathrm{~km} / \mathrm{h}$ ), the rail and wheel may suffer a secondary fracture. The damage tolerance of rail fracture length is $60 \mathrm{~mm}$ for high-speed railways.

Acknowledgements The work is supported by the National Natural Science Foundation of China (Nos.51608459, 51778542 and U1734207) and Fundamental Research Funds for the Central Universities (No.2682018CX01) and Cultivation Program for the Excellent Doctoral Dissertation of Southwest Jiaotong University.

Open Access This article is licensed under a Creative Commons Attribution 4.0 International License, which permits use, sharing, adaptation, distribution and reproduction in any medium or format, as long as you give appropriate credit to the original author(s) and the source, provide a link to the Creative Commons licence, and indicate if changes were made. The images or other third party material in this article are included in the article's Creative Commons licence, unless indicated otherwise in a credit line to the material. If material is not included in the article's Creative Commons licence and your intended use is not permitted by statutory regulation or exceeds the permitted use, you will need to obtain permission directly from the copyright holder. To view a copy of this licence, visit http://creativecommons. org/licenses/by/4.0/.

\section{References}

1. Tong D (1986) Railroad track. China Railway Publishing House, Beijing

2. Gonzalez FJ, Suarez B, Paulin J et al (2008) Safety assessment of underground vehicles passing over highly resilient straight track in the presence of a broken rail. J Rail Rapid Transit 222(1):69-84

3. Suarez B, Fernandez I (2012) Safety assessment of underground vehicles passing over highly resilient curved tracks in the presence of a broken rail. Veh Syst Dyn 50(1):59-78

4. Schafer DH, Barkan CPL (2008) A hybrid logistic regression/ neural network model for the prediction of broken rails. In: Proceedings of the 8th world congress on railway research, Seoul

5. Allan Z (2009) Guidelines for broken-rail risk. Railw Track Struct 105:37-41

6. Matsuda H, Satoh Y, Kanematsu Y et al (2011) On-site investigation and analysis of flaking damage leading to rail break. Wear 271(1-2):168-173

7. Cai X, Cai X, Zhu B (2014) Research on dynamic characteristics of high-speed vehicle-track under condition of broken rail gap. 
In: The 3rd international conference on railway engineering, Beijing

8. Ekberg A, Kabo E (2014) Surface fatigue initiated transverse defects and broken rails-an international review. Chalmers University of Technology, Gothenburg

9. Magel E, Mutton P, Ekberg A et al (2016) Rolling contact fatigue, wear and broken rail derailments. Wear 366-367:249-257

10. Tai B, He J, Liu X (2016) A preliminary methodology for broken rail caused freight train derailment risk analysis. In: 2016 Joint Rail Conference, Columbia

11. Sheperd D, Magel E, Harris B (2016) The impact of RCF and wear on service failures and broken rail derailments. In: AREMA Annual Conference, Warwickshire

12. An R, Sun Q, Bai W et al (2017) Grid-based analysis of causal factors of railway rail break risk. In: Transportation Research Board 96th annual meeting, Washington DC

13. Thurston DF (2014) Risk based broken rail detection on railways. In: 2014 Joint Rail Conference, Colorado Springs

14. Wei X, Yang Y, Yu N (2017) Research on broken rail real-time detection system for ultrasonic guided wave. In: 2017 International Conference on Electromagnetics in Advanced Applications (ICEAA), Verona

15. Thurston DF (2014) Broken rail detection: practical application of new technology or risk mitigation approaches. IEEE Veh Technol Mag 9(3):80-85

16. Wen Z, Xiao G, Jin X et al (2009) Dynamic vehicle-track interaction and plastic deformation of rail at rail welds. Eng Fail Anal 16(4):1221-1237
17. Braghin F, Bruni S, Diana G (2006) Experimental and numerical investigation on the derailment of a railway wheelset with solid axle. Veh Syst Dyn 44(4):305-325

18. China Academy of Railway Sciences (2007) Dynamic performance test report for non-ballast track structure and fastening system. China Academy of Railway Sciences, Beijing

19. Chen R, Hu C, Xu J et al (2018) An innovative and efficient method for reverse design of wheel-rail profiles. Appl Sci 8(2):239-256

20. An B, Wang P, Xu J et al (2017) Oberservation and simulation of axle box acceleration in the presence of rail weld in high-speed railway. Appl Sci 7(12):1259

21. Mandal NK (2014) On the low cycle fatigue failure of insulated rail joints (ITJS). Eng Fail Anal 40:58-74

22. Mandal NK (2014) Ratchetting of railhead material of insulated rail joints (IRJS) with reference to endpost thickness. Eng Fail Anal 45:364-374

23. Mohammadzadeh S, Sharavi M, Keshavarzian H (2012) Reliability analysis of fatigue crack initiation of railhead in bolted rail joint. Eng Fail Anal 29:132-148

24. Chaar N, Berg M (2006) Simulation of vehicle-track interaction with flexible wheelsets, moving track models and field tests. Veh Syst Dyn 44(sup1):921-931

25. Hallquist JO (2006) LS-DYNA theory manual. Livermore Software Technology Corporation, Livermore

26. Tian Y, Cheng Y, Liu X (1992) Studies on the dynamic behavior of U71MN rail steel under high strain rates. China Railw Sci 13:32-42 (in Chinese) 